\title{
Зависимость объемного тока крови через коронарные анастомозы от техники наложения шва и шовного материала
}

\author{
Галич С. С., Руденко А. В., Настенко Е. А. Стародуб Ю. С. \\ ГУ «Национальный институт сердечно-сосудистой хирургии \\ имени Н. М. Амосова НАМН Украины» (Киев)
}

\begin{abstract}
В работе представлено сравнение объемных скоростей кровотока в двух группах коронарных анастомозов, которые в первой группе отличалась между собой техникой наложения швов, а во второй - диаметром шовной нити. Все исследование проводилось на одних и тех же парах сосудов. Результаты исследования указывают, что значительных отличий в пропускной способности анастомозов, созданных с использованием разных техник, не наблюдалось $(\mathrm{p}>0,05)$, тогда как использование шовного материала меньшего диаметра (8/0 полипропилен) значительно $(\mathrm{p} \leq 0,01)$ увеличивает объемный ток крови через коронарный анастомоз. Таким образом, представленные техники наложения швов могут одинаково использоваться в коронарной хирургии, тогда как использование шовного материала с нитью меньшего диаметра является предпочтительным для коронарного шунтирования.
\end{abstract}

Ключевые слова: коронарный анастомоз, объемный кровоток, техника анастомоза, шовный материал.

Известно, что ранние нарушения функционирования коронарных шунтов в большинстве случаев являются следствием технических погрешностей, в частности, в области дистальных анастомозов [1]. Определение объемного кровотока по коронарному шунту является качественной характеристикой выполненного коронарного анастомоза. В конце 90-х годов стал доступным новый простой и легкий в применении метод оценки объемного кровотока - transit time flow meter (TTFM). Этот метод дает возможность определить значение объемного кровотока, форму кривой потока, процент диастолического кровотока в коронарном шунте и индекс пульсации, что позволяет комплексно оценить качество коронарного анастомоза [8].

Вопросу техники выполнения коронарного анастомоза в литературе уделяется недостаточное внимание, а все данные являются редкими и зачастую противоречивыми. Так, многие хирурги используют парашютную технику выполнения анастомоза (Hendrick B. Barner, 2013) [2]. Также существует практика использования П-образных швов, хотя некоторые хирурги выступают категорически против этой техники выполнения анастомозов, поскольку считают, что такие швы могут вызывать сужение просвета анастомоза (И. Литтманн, 1985) [3]. Шовный материал в коронарной хирургии используется разный - на усмотрение оперирующего хирурга. Обычно коронарные анастомозы формируются с помощью нити 7-0 полипропилен (Prolene) (Donald B. Doty, 2012, Lowrence H. Cohn, 2008, Giuseppe D’Ancona, 2009) [4-6]. Однако некоторые хирурги считают, что такая нить подходит только для аутовенозно-коронарных анастомозов, тогда как для аутоартериально-коронарных допустимо использование лишь 8-0 Prolene (Акчурин Р. С., 2012) [1].

Хотя в настоящее время существуют достаточно разные методики выполнения коронарного анастомоза с использованием разного шовного материала, до сих пор в мировой литературе не представлен определенный перечень требований к конфигурации коронарного анастомоза и правила его выполнения.

Цель работы - сравнить объемную скорость кровотока через коронарные анастомозы, созданные с использованием разных методик наложения швов и разного шовного материала.

Материалы и методы. В данной работе рассмотрены результаты исследования объемного кровотока в лабораторных условиях через коронарные анастомозы по типу «конец в бок», выполненные в первой группе исследований тремя разными способами и во второй группе - с использованием разного шовного материала. Сравнение объемных потоков крови проводилось на одних и тех же парах сосудов. Анастомозы создавались между артериальными (диаметром от 1,5 до 3 мм) и венозными (диаметром от 3,5 мм до 5 мм) сосудами и коронарными артериями. Все исследуемые методики наложения коронарного анастомоза широко используются в современной коронарной практике. Для определения объемного кровотока через созданный коронарный анастомоз по шунту при постоянном давлении пропускался раствор, представляющий собой смесь дистиллированной воды и глицерина в пропорциях 7,5:7 для достижения относительной вязкости раствора, идентичной вязкости крови $-4,5$. Измерения объемного тока жидкости проводились с помощью метода 

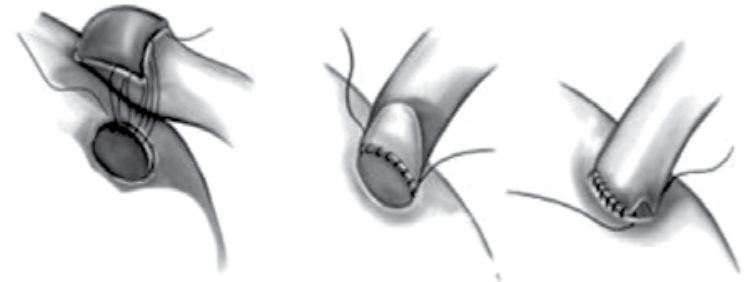

Рис. 1. «Парашютный» способ

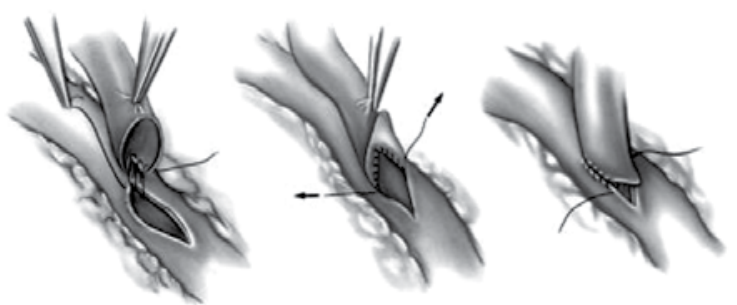

Рис. 2. Техника «fish-mouth» «transit time flow meter» (TTFM). Изменяя технику выполнения коронарного анастомоза, определяли степень ее влияния на объемный кровоток через него.

В группе сравнения разных техник выполнения анастомоза (27 анастомоза) сравнивались «парашютная» техника, техника с завязыванием узла первого стежка на пятке анастомоза и наложение П-образного стежка на пятку анастомоза. Парашютная техника является наиболее распространенной в коронарной практике. Техника наложения П-образного стежка на пятке коронарного анастомоза считается укрепляющей коронарный шов. По мнению некоторых хирургов, завязывание узла на первом стежке коронарного шва позволяет уменьшить степень сужения анастомоза при завязывании узла. Все три техники встречаются в коронарной хирургии и заслуживают изучения и сравнения их влияния на пропускную способность анастомозов. Для этого были созданы 9 троек анастомозов с коронарными артериями (1,0-1,5 мм в диаметре) и венозными шунтами с диаметром 3,0-4,0 мм.

Первыми создавались анастомозы парашютной техникой (рис. 1). Швы анастомоза расшивались. Затем второй анастомоз между теми же сосудами создавался с наложением П-образного стежка на пятке шунта (рис. 2). Анастомоз создавался с помощью техники «fish-mouth», когда после наложения П-образного шва «снаружи внутрь» просвета шунта и прошивания коронарной артерии обеими нитями сосуды соединяются сразу и дошиваются, постепенно укладываясь соответствующими зонами анастомоза. Последним, после расшивания предыдущего, выполнялся третий анастомоз, начиная с завязывания узла на первом стежке, что в теории должно препятствовать образованию кисета и чрезмерному затягиванию шва анастомоза с сужением просвета анастомоза. После создания каждого из анастомозов оценивалась его пропускная способность (объемный кровоток через него).

Группа сравнения шовного материала (54 анастомоза) представлена 18 тройками анастомозов, где сравнивались три разных диаметра шовного материала - 6/0, 7/0 и 8/0 полипропилен (Prolene).

Первые анастомозы в каждой тройке выполнялись с использованием 8/0 Prolene, затем анастомоз расшивался и заново выполнялся с использованием материала 7/0 Prolene, затем использовался 6/0 Prolene.

Результаты исследования. Результаты сравнения влияния техники выполнения коронарных анастомозов на их пропускную способность представлены на рис. 3.

Средняя пропускная способность анастомозов при использовании первого метода (метод 1) составляла 82,5 $\pm 25,0$ мл/мин., второго метода (метод 2) $-75,1 \pm 16,9$ мл/мин., третьего метода (метод 3) $76,3 \pm 26,1$ мл/мин. Исследование отличий в пропускной способности анастомозов проводилось с помощью дисперсионного анализа. Статистически достоверной разницы в использовании разных техник не наблюдалось $(\mathrm{p}=0,157)$.

Результаты исследования пропускной способности анастомозов, созданных с использованием разных шовных нитей, представлены на рис. 4.

Результаты сравнения объемных кровотоков через анастомозы указывают на значительное влияние шовного материала на пропускную способность коронарных анастомозов. Средняя пропускная способность анастомозов при использовании 8/0 Prolene составила

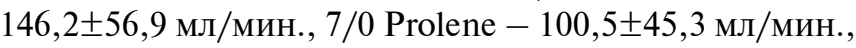

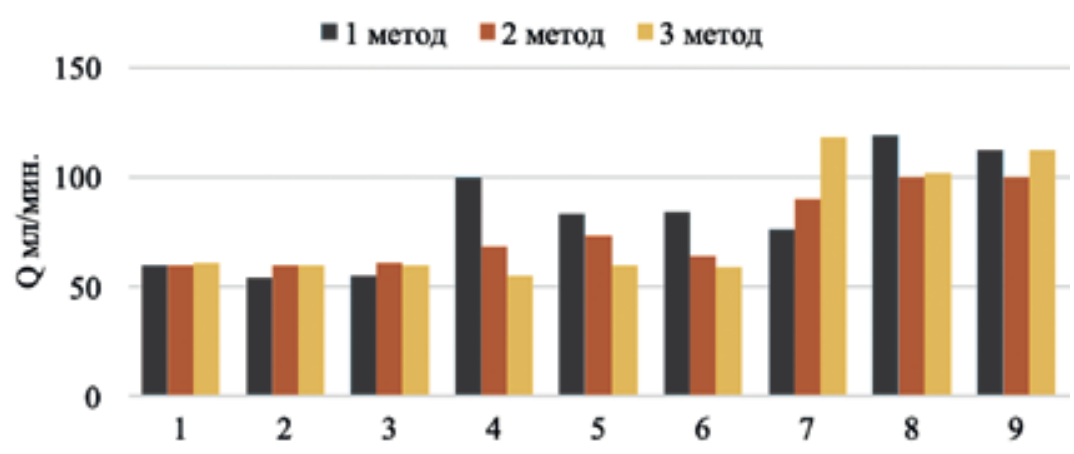

Рис. 3. Сравнение объемных кровотоков в группе разных техник выполнения анастомозов ( $Q$ - объемный кровоток через анастомозы) 


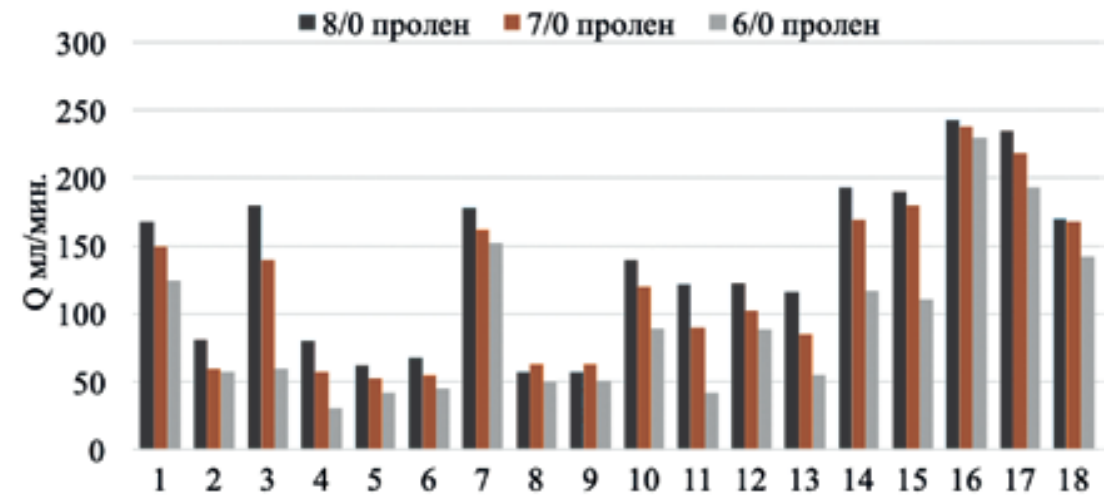

- Рис. 4. Сравнение объемных кровотоков в группе разного шовного материала (18 троек); Q - объемный кровоток через анастомозы ронарные анастомозы с наименьшей деформацией шовной линии по сравнению с более крупной нитью (6/0 Prolene). Более крупный диаметр нити гофрирует шов анастомоза, который сужает его просвет, что мы наблюдали в исследованиях IVUS, и снижает объемный кровоток через него. При этом такое гофрирование шва может незначительно уменьшать объемный кровоток (на 16\%, как было при исследовании IVUS) при работе с крупными сосудами (3,0-3,5 мм), тогда как для коронарных артерий с диаметром $\leq 1,5$ мм при использовании 8/0 Prolene такая деформация шва приводит к значительным изменениям в пропускной способности (снижение до 60\%). Такое мне-

6/0 Prolene - 102,9 $\pm 59,5$ мл/мин. Выявлено значительное преимущество шовной нити 8/0 Prolene $(\mathrm{p} \leq 0,001)$.

Для коронарных артерий диаметром $\leq 1,5$ мм использование 8/0 Prolene увеличивало объемный кровоток через анастомоз на $10-33 \%$ по сравнению с нитью 7/0 Prolene и на 20-160\% по сравнению с нитью $6 / 0$ Prolene $(p \leq 0,001)$.

Для коронарных артерий диаметром $>1,5$ мм отличия в пользу шовного материала 8/0 Prolene достигали $50 \%$ при сравнении с 7/0 Prolene и до $100 \%$ - при сравнении с 6/0 Prolene ( $\leq \leq 0,001)$.

Обсуждение. Результаты сравнения объемных кровотоков через коронарные анастомозы указывают на то, что парашютная техника, которая используется большинством хирургов, оказывает одинаковое влияние на пропускную способность анастомоза по сравнению с техникой П-образного шва на пятке и техникой завязывания узла на первом стежке коронарного шва. Поэтому, несмотря на мнение И. Литтмана (1985) о сужении просвета при использовании П-образного шва, все перечисленные техники не влияют на пропускную способность коронарного анастомоза. Определение кровотока через коронарные анастомозы показало, что по сравнению с нитью более крупного диаметра (6/0 Prolene) нити меньшего диаметра (8/0 Prolene) позволяли значительно увеличить объемный кровоток через коронарные анастомозы. В результате проведенного нами ранее внутрисосудистого ультразвукового исследования (IVUS) внутреннего строения анастомозов, созданных с использованием шовных нитей разного диаметра (8/0 и 6/0 Prolene) также были отмечены явные преимущества материала 8/0 Prolene [8]. Результаты исследования показали, что нить 8/0 Prolene позволила увеличить размеры анастомоза по сравнению с 6/0 Prolene: на 12,5\% продольный диаметр, на 13,0\% - поперечный, на 25\% общую площадь анастомоза.

По нашему мнению, шовный материал наименьшего диаметра (8/0 Prolene) позволяет создавать ко- ние также высказывали и некоторые зарубежные ученые $[9,10]$. Поэтому шовный материал наименьшего диаметра (8/0 Prolene) считаем наиболее подходящим с точки зрения максимальных показателей объемного кровотока и внутренних параметров анастомозов, созданных с его использованием. Такие рекомендации совпадают с рекомендациями проф. Р. С. Акчурина и А. А. Ширяева (2012) [1], приведенными в книге «Микрохирургия коронарных артерий», где для шва аутовенозно-коронарного анастомоза советуют использовать нить 7/0 или 8/0 Prolene, тогда как для аутоартериально-коронарного анастомоза - только нить 8/0 Prolene. Также в реконструктивной микрохирургии под редакцией В. М. O’Brien [7] указываются преимущества применения тонкого микрохирургического шовного материала 8-0 и 9-0 для сшивания артерий малого калибра. Можем не согласиться с мнением Donald B. Doty (2012), который предлагает использовать условный номер нити 7/0 для всех видов дистальных анастомозов.

Выводы. Значительных отличий в результатах исследования пропускной способности анастомозов, созданных с использованием разных техник, не наблюдалось $(\mathrm{p}>0,05)$. При этом результаты сравнения объемных кровотоков через анастомозы, созданные с использованием шовного материала нитей разного диаметра (8/0, 7/0, 6/0 Prolene), указывают на значительное влияние использованного шовного материала на их пропускную способность. Шовный материал 8/0 Prolene увеличивал объемный кровоток через анастомозы по сравнению с остальными нитями $(\mathrm{p} \leq 0,001)$, что было особенно явно заметно при шунтировании коронарных артерий малого диаметра ( $\leq 1,5$ мм).

\section{Литература}

1. Акчурин Р. С., Ширяев А. А. Микрохирургия коронарных артерий: руководство. - М. : ГЭОТАРМедиа, 2012. - С. 74-80. 
2. Hendrick B. Barner. Conduits for Coronary Bypass: Arteries Other Than the Internal Thoracic Artery's Korean. J Thorac Cardiovasc Surg 2013;46:165-177.

3. Оперативная хирургия / под общей редакцией проф. И. Литтманна. Издательство Академии наук Венгрии - AKADEMIAI KIAD6. Будапешт, 1985. C. 785-787.

4. Cardiac surgery: operative technique / Donald B. Doty, John R. Doty with illustrations by Jill Rhead, Cristy Krames. - 2-nd edition. 2012 by Saunders.

5. Lowrence H. Cohn, MD. Cardiac Suregry in the Adult / Third edition / Copyright 2008 by The McGraw-Hill Companies.

6. Giuseppe D'Ancona / Intraoperative Flow Measurement in Coronary Artery Surgery 2009 Optima Grafische Communicatie, Rotterdam, The Netherlands.
7. O’Brien B. M., MacLeod A. M. Morrison. Microvascular Reconstructive Surgery April 4,1977. Hardcover.

8. Использование ультразвукового внутрисосудистого исследования (IVUS) для определения оптимальных условий формирования коронарного анастомоза / Руденко А. В., Сало С. В., Галич С. С., Гаврилишин А. Ю. // Вісник серцево-судинної хірургії. 2015. - Вип. 23. - С. 219-23.

9. Tsukui H, Shinke M, Park YK, Yamazaki K. Longer coronary anastomosis provides lower energy loss in coronary artery bypass grafting. Heart Vessels. 2017 Jan;32(1):83-89. doi: 10.1007/s00380-016-0880-4.

10. Marc Gerdisch, Thomas Hinkamp, Stephen D. Ainsworth. Blood Flow Pattern and Anastomotic Compliance for Interrupted versus Continuous Coronary Bypass Grafts. The Heart Surgery Forum \#2002-24200 6 (2), 2003.

\title{
Influence of the anastomotic techniques and suture material performing coronary anastomosis on volumetric flow rate
}

\author{
Galych S., Rudenko A., Nastenko E., Starodub Y.
}

National M. M. Amosov Institute of Cardiovascular Surgery National Academy of Medical Sciences of Ukraine (Kyiv)

In our study we represent the comparisons of the volumetric blood flow velocities in two groups of coronary anastomoses, which in the first group differed by the technique of suturing, and in the second group - by the diameter of the suture thread. All coronary anastomoses were constructed between porcine vessels. Comparison of the volumetric flow rates through the anastomoses, depending on the technique and suture material, was carried out on the same vascular pairs for maximum purity of the experiment. The results of our investigation revealed that significant differences in the capacity of anastomoses created using different techniques were not observed $(p>0.05)$, while the use of a suture material of smaller diameter $(8 / 0)$ significantly ( $\mathrm{p} \leq 0.01)$ increases the volume flow of blood through the coronary anastomosis up to $10-33 \%$ compared to the $7 / 0$ thread and up to $100 \%$ compared to the $6 / 0$ filament. Such differences are especially noticeable when grafting coronary arteries of small diameter $(\leq 1.5 \mathrm{~mm})$. Thus, it should be considered that the configurations of coronary anastomoses created by three different methods of suturing are insignificantly different from each other and can equally be used in coronary surgery. However, the use of suture material with a thread of smaller diameter (8/0 Prolene) significantly increases the volume velocity of blood flow through the anastomosis and should preferably be used for coronary bypass surgery.

Key words: coronary anastomosis, volumetric flow rate, anastomotic technique, suture material

\section{Залежність обєєного току крові через коронарні анастомози від техніки накладання шва та шовного матеріалу}

\author{
Галич С. С., Руденко А. В., Настенко Е. А., Стародуб Ю. С.
}

ДУ «Національний інститут серцево-судинної хірургії імені М. М. Амосова НАМН України» (Київ)

У роботі представлено порівняння об’ємних швидкостей кровотоку в двох групах коронарних анастомозів, які в першій групі відрізнялася між собою технікою накладання швів, а в другій - діаметром шовної нитки. Коронарні анастомози створювалися на свинячих судинах. Порівняння об'ємних швидкостей кровотоку через анастомози залежно від техніки та шовного матеріалу проводилося на одних і тих самих парах судин для максимальної чистоти експерименту. Результати дослідження вказують, що значних відмінностей у пропускній здатності анастомозів, створених із використанням різних технік, не спостерігалося (p $>0,05)$, тоді як використання шовного матеріалу меншого діаметра $(8 / 0$ поліпропілен) значно $(\mathrm{p} \leq 0,01)$ збільшує об'ємний потік крові через коронарний анастомоз - до 10-33\% порівняно з ниткою 7/0 поліпропілен і до $100 \%$ порівняно з ниткою 6/0 поліпропілен. Такі відмінності особливо помітні під час шунтування коронарних артерій малого діаметра ( $\leq 1,5$ мм). Таким чином, слід вважати, що конфігурації коронарних анастомозів, створених трьома різними способами накладення швів, незначно відрізняються один від одного і можуть однаково використовуватися в коронарній хірургії. При цьому використання шовного матеріалу з ниткою меншого діаметра (8/0 поліпропілен) значно збільшує об;ємну швидкість кровотоку через анастомоз, тому саме цей шовний матеріал має переважати (або: має бути пріоритетним) при коронарному шунтуванні.

Ключові слова: коронарний анастомоз, об’ємний кровотік, техніка анастомозу, шовний матеріал. 